\title{
The Effect of Composition on the Mechanical Properties of Alkali-activated Fly Ash-Portland Cement Binary System
}

\author{
Jun LIU \\ School of materials science and engineering \\ Shenyang Jianzhu University \\ Shenyang Liaoning, China \\ e-mail: liujun2699@126.com \\ Runqing LIU \\ School of materials science and engineering \\ Shenyang Ligong University \\ Shenyang Liaoning, China \\ e-mail: 13940195514@163.com
}

\author{
Jinyu FU \\ School of materials science and engineering \\ Shenyang Jianzhu University \\ Shenyang Liaoning, China \\ e-mail: fjy427427@126.com \\ Yuanquan YANG \\ School of materials science and engineering \\ Shenyang Ligong University \\ Shenyang Liaoning, China \\ e-mail: aquarius0109@163.com
}

\begin{abstract}
The effects of fly ash, lime, alkali activator and styrene-acrylic emulsion on the compressive strength and flexural strength of fly ash cement were studied in this paper. The results show that the addition of fly ash can improve the workability of mortar, but it will reduce the strength of the material. Adding lime can effectively improve the strength of cementitious material. The strength of cementitious material increases with the increase of alkali activator dosage. The cementitious material with no more than $1 \%$ styrene-acrylic emulsion can effectively improve the strength of cementitious materials, which plays a toughening effect.
\end{abstract}

Keywords-fly ash; lime; alkali activator; styrene-acrylic emulsion; strength

\section{INTRODUCTION}

China is a coal-rich country and with the continuous development of thermal power industry, a large number of thermal power by-product of fly ash accumulated, which pollutes the environment. With the development of science and technology, as active mineral admixtures fly ash are widely used in concrete engineering and have achieved very good results, which have also captured the attention of the domestic and foreign experts and scholars to fly ash-cement compound cementing material and its performance has been done a lot of research.

The role of fly ash can be roughly summarized as morphological effects, micro-aggregate effect and ash effects [1]. Fly ash is formed under the condition of high temperature flow. After cooling, many fly ash particles keep the glassy phase structure at high temperature, which makes the active $\mathrm{Al}_{2} \mathrm{O}_{3}$ and $\mathrm{SiO}_{2}$ difficult to dissolve out. The structure of high alumina, low calcium and high silicon [ $(\mathrm{Si}$, Al) $\left.\mathrm{O}_{4}\right]_{\mathrm{n}}$ is also very strong, which is not easily broken into $\left[\mathrm{AlO}_{4}\right],\left[\mathrm{SiO}_{4}\right]$ and other monomers [2]. This can be ameliorated by fly ash excitation, which breaks the bonds formed between the vitreous bodies and thereby excites the potential activity of the fly ash.
At present, physical excitation, chemical excitation, physical and chemical excitations are commonly used in several ways to activate the fly ash [3]. Physical excitation is mainly achieved by fly ash grinding to increase its participation in the hydration reaction of the interaction area. Chemical excitation includes alkali activator, salt stimulant, acid and other stimulants. Physicochemical excitation includes high temperature activation method and pretreatment methods. Physical excitation and physical and chemical excitation in the actual research process is more complex, most of the major research experts or chemical excitation method choose to add chemical reagents to the cementing material, which can have a good excitation effect [4].

In this paper, $0 \%, 10 \%, 20 \%, 30 \%, 40 \%$ fly ash are used to replace the cement by mass, and chemical alkali excitation is used to investigate the effect of lime, alkali activator and styrene on the strength of fly ash-Portland blended cement mortar.

\section{EXPERIMENT}

\section{A. Materials}

The main chemical composition of the Portland cement is shown in Table I. The main chemical composition of fly ash is shown in Table II. In the experiment, lime, sodium silicate and sodium hydroxide were also used in the experiment. The main chemical composition of the ordinary Portland cement (PO42.5) is produced by Dalian Onoda Cement Co. Superplasticizer, early strength agent and sand are used in this experiment.

TABLE I. ChEMICAL COMPOSITION OF CEMENT (\%)

\begin{tabular}{cccccccc}
\hline $\mathrm{SiO}_{2}$ & $\mathrm{Al}_{2} \mathrm{O}_{3}$ & $\mathrm{Fe}_{2} \mathrm{O}_{3}$ & $\mathrm{CaO}$ & $\mathrm{MgO}$ & $\mathrm{SO}_{3}$ & $\mathrm{R}_{2} \mathrm{O}$ & $\begin{array}{c}\text { loss on } \\
\text { ignition }\end{array}$ \\
\hline 21.63 & 5.72 & 4.28 & 62.19 & 1.82 & 2.64 & 0.72 & 1.47 \\
\hline
\end{tabular}


TABLE II. CHEMICAL COMPOSITION OF FLY ASH (\%)

\begin{tabular}{cccccccc}
\hline $\mathrm{SiO}_{2}$ & $\mathrm{Al}_{2} \mathrm{O}_{3}$ & $\mathrm{CaO}$ & $\mathrm{MgO}$ & $\mathrm{Fe}_{2} \mathrm{O}_{3}$ & $\mathrm{~K}_{2} \mathrm{O}$ & $\mathrm{Na}_{2} \mathrm{O}$ & $\mathrm{SO}_{3}$ \\
\hline 59.95 & 26.78 & 4.35 & 2.30 & 1.53 & 1.25 & 2.75 & 1.46 \\
\hline
\end{tabular}

\section{B. Mortar Mix Design}

Based on the preliminary test, the basic proportion of fly ash to ordinary Portland cement of 2:3, $10 \%$ lime, $15 \%$ alkali activator, $2 \%$ hardening accelerator, $1 \%$ water agent, cement to mortar of 1: 3 , water to cement ratio of 0.45 are designed. In this paper, fly ash, lime, alkali activator and styrene-acrylic emulsion were selected as four variables, the substitution of Portland cement by fly ash were $0 \%, 10 \%$, $20 \%, 30 \%$ and $40 \%$, respectively. Lime content was $0 \%, 6 \%$, $8 \%, 10 \%, 12 \%$. The content of alkali activator was $0 \%, 5 \%$, $10 \%, 15 \%$ and $20 \%$ respectively. The content of styreneacrylic emulsion was $0.2 \%, 0.4 \%, 0.8 \%, 1 \%$ and $1.2 \%$ respectively.

\section{RESUlTS AND DisCUSSIONS}

\section{A. Effect of Lime Content on the Mechanical Properties of} Fly Ash-Portland Blended Cement

$\mathrm{Ca}^{2+}$ is a prerequisite for the hydration of fly ash. The increase of $\mathrm{Ca} / \mathrm{Si}$ ratio can improve the activity of fly ash. Otherwise, it is difficult to produce cementitious products such as $\mathrm{C}-\mathrm{S}-\mathrm{H}$ and $\mathrm{C}-\mathrm{A}-\mathrm{H}$ which can provide early strength in early stage of fly ash. The compressive strength and flexural strength of fly ash-cement mortar were measured according to the addition of lime.

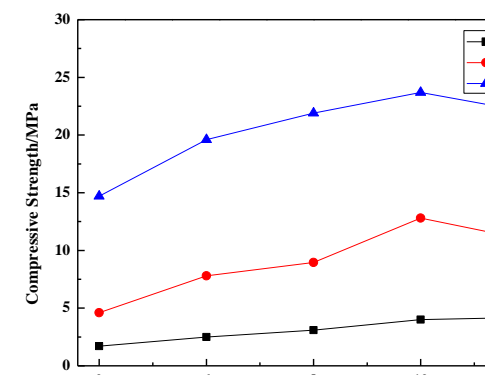

Figure 1. Effect of different lime content on flexural strength

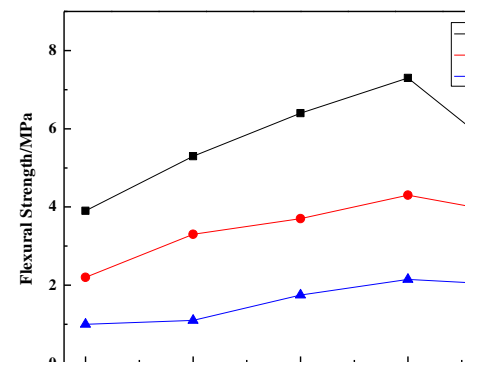

Figure 2. Effect of different lime content on compressive strength

The influence of lime content on the flexural strength of fly ash-cement mortar is shown in Fig.1. From Fig.1, we can see that with the increase of lime content, the flexural strength of fly ash-cement mortar gradually increased, while the excess lime will adversely affect the flexural strength of fly ash-cement mortar. The flexural strength of fly ash cement mortar showed the best performance at all ages $(3 \mathrm{~d}$, $7 \mathrm{~d}$ and $28 \mathrm{~d}$ ), and its flexural strength reached $2.15 \mathrm{MPa}$, 4.3 $\mathrm{MPa}$ and7.3MPa. When the addition of lime is low $(0-$ $6 \%$ ), the flexural strength of fly ash-cement mortar increases slowly with the increase of the content. For example, when the content increases from $6 \%$ to $8 \%$ the flexural strength of mortar increased by $34.6 \%, 12.12 \%$ and $20.75 \%$ at $3 \mathrm{~d}, 7 \mathrm{~d}$ and $28 \mathrm{~d}$, respectively. The increase of flexural strength was more obvious when the content increased from $8 \%$ to $10 \%$, and the strength increased by $22.86 \%, 16.2 \%$ and $14.06 \%$ at $3 \mathrm{~d}, 7 \mathrm{~d}$ and $28 \mathrm{~d}$, respectively. When the lime content is $10 \%$, the flexural strength of fly ash-cement reaches the optimal value, but when it exceeds $10 \%$, the flexural strength of the test piece begins to decrease, especially the strength of $28 \mathrm{~d}$, which decreases by $30.14 \%$.

The influence of lime content on the compressive strength of fly ash-cement mortar is shown in Fig.2. The compressive strength varied with the flexural strength at the same time, and the strength reached the optimum value at the dosage of $10 \%$. The compressive strength at each age (3d, $7 \mathrm{~d}$ and $28 \mathrm{~d}$ ) was $4.0 \mathrm{MPa}, 10.5 \mathrm{MPa}$ and $16.8 \mathrm{MPa}$. The increasing trend of compressive strength at different ages (3d, $7 \mathrm{~d}$ and $28 \mathrm{~d}$ ) was increased by $29.03 \%, 30.07 \%$ and $7.5 \%$, respectively. When the content increased from $8 \%$ to $10 \%$, the compressive strength showed a downward trend, indicating that too much lime will volume instability of the cement mortar, which led to a decline in compressive strength.

During the test, it was found that the strength of the mortar specimen was lower than that without lime, which proved the importance of $\mathrm{Ca} 2+$ in the fly ash-cement system. When the lime content is less than $8 \%$, the strength of alkali-activated fly ash cementitious system is low at all ages, which indicates that the $\mathrm{Ca} 2+$ content in the system is not enough and can not satisfy the comprehensive calciumsilicon system. The calcium ion content is not enough to generate an effective structure, and thus the amount of lime in the system should not be less than $8 \%$, but not more than $10 \%$.

\section{B. Fly Ash Content on the Mechanical Properties of Fly Ash - Cement Mortar}

In order to improve the utilization of fly ash, the effect of fly ash content on the mechanical properties of fly ash cement was studied. According to the basic mixing ratio of the test, the content of fly ash was adjusted, and the compressive strength and flexural strength of fly ash cement mortar were measured.

The effect of fly ash content on the flexural strength of fly ash-cement mortar is shown in Fig.3. It can be seen from Figure 3 that with the increase of fly ash content, flexural strength of the mortar decreases slowly. The flexural strength was $3.15 \mathrm{MPa}$ at $3 \mathrm{~d}, 7.8 \mathrm{MPa}$ at $7 \mathrm{~d}$, and $10.85 \mathrm{MPa}$ at $28 \mathrm{~d}$ without adding fly ash. When the fly ash content varied from $0 \%$ to $10 \%$, the flexural strength of the mortar at the associated age declined slowly. When the fly ash content 
gradually increased from $10 \%$ to $20 \%$, the flexural strength of the mortar at $3 \mathrm{~d}, 7 \mathrm{~d}$ and $28 \mathrm{~d}$ declined rapidly by about $27.59 \%, 23.5 \%$ and $16.17 \%$. When the fly ash content increased from $20 \%$ to $30 \%$, the flexural strength at $7 \mathrm{~d}$ decreased slowly by $10.58 \%$. When the content of fly ash increased from $40 \%$ to $50 \%$, the flexural strength of mortar at $3 \mathrm{~d}$ tends to decrease, but the flexural strength decreases at $7 \mathrm{~d}$ and $28 \mathrm{~d}$.

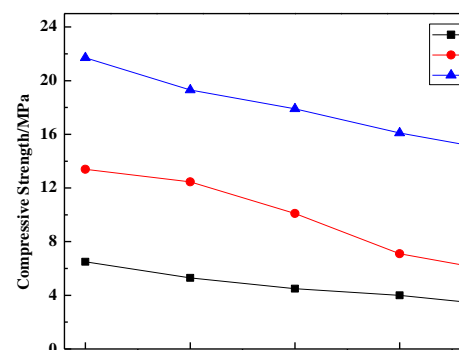

Figure 3. Effect of different fly ash content on compressive strength

The effect of fly ash content on the compressive strength of fly ash-cement mortar is shown in Fig.4. As can be seen from Figure 4, the strength of the sample without fly ash can reach $21.7 \mathrm{MPa}$ after curing for $28 \mathrm{~d}$. With the increase of fly ash content, the strength of mortar $3 \mathrm{~d}, 7 \mathrm{~d}$ and $28 \mathrm{~d}$ showed a decreasing trend, and the decreasing trend was obvious. The compressive strength of mortar decreased by $56.4 \% 74.5 \%$ and $63.7 \%$ at $3 \mathrm{~d}, 7 \mathrm{~d}$ and $28 \mathrm{~d}$, respectively. When the amount of fly ash is too large, the cement content is relatively insufficient; the volcanic ash of fly ash reacts slowly and can not fully react, so the strength decreases greatly.

With the continuous increase of fly ash content, the mechanical properties of mortar decreased significantly, because the increase in fly ash led to less ettringite, resulting in lower specimen strength, especially at the $3 \mathrm{~d}$ period the fly ash almost did not participate in the hydration reaction, but played the role of micro-aggregate filler. So the flexural strength and compressive strength of the mortar are low. But with the increase of fly ash content, the mortar demands less water, the fluidity of mortar increases, which is beneficial to the workability of mortar.

\section{The Effect of Alkali Activated Agent on the Mechanical Properties of Fly Ash - Cement Mortar}

Based on previous studies, the experiment using a single alkali excitation agent to stimulate fly ash, fly ash is found at room temperature difficult to be completely excited out of pozzolanic activity. Many people are studying the use of high temperature activation of fly ash activity, or the use of steam curing system. However, this method in reality is difficult to use in the project, thus the choice of study in this study at room temperature using a complex alkali activator to stimulate the activity of fly ash. The composite activator consists of sodium hydroxide and sodium silicate, and the water glass modulus is adjusted to 1.2 with sodium hydroxide. The compressive strength and flexural strength of fly ash - cement mortar were measured according to the mixing proportion of the basic activator.

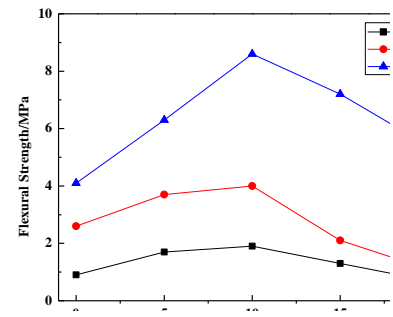

Figure 4. Effect of different alkali activator dosage on flexural strength

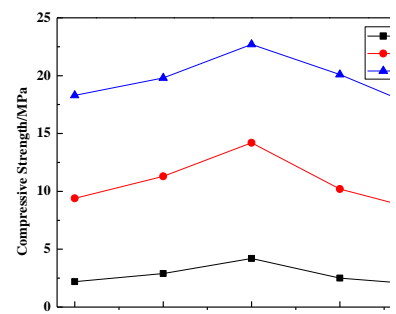

Figure 5. Effect of different alkali activator dosage on compressive strengt

The effect of different amount of alkali activator on the flexural strength of mortar is shown in Fig.5. From Fig.5, it can be seen that the flexural strength of specimens increases with the increase of the alkali content. When the dosage increases from $5 \%$ to $10 \%$, the strength increases at $3 \mathrm{~d}$ and $7 \mathrm{~d}$. When the content of alkali activator reached $10 \%$, the strength reached the optimum value, and the flexural strength of each age $(3 \mathrm{~d}, 7 \mathrm{~d}$ and $28 \mathrm{~d})$ reached $1.3 \mathrm{MPa}$, $2.1 \mathrm{MPa}$ and $7.2 \mathrm{MPa}$ respectively. When the content of alkali is increased from $10 \%$ to $15 \%$, the strength reduction rate is larger, and the flexural strength of each age $(3 \mathrm{~d}, 7 \mathrm{~d}$ and $28 \mathrm{~d}$ ) decreases by $31.58 \% \%, 47.5 \%$ and $16.28 \%$ respectively.

The effect of different alkali activator on compressive strength of mortar is shown in Fig.6. The influence of alkali activator on compressive strength of mortar is similar to that of flexural strength. With the increase of alkali activator, the strength of alkali activated fly ash cementing material increases first and then decreases. When the content of alkali activator reached $10 \%$, the compressive strength reached the maximum at each age, which was $2.7 \mathrm{MPa}$, 9.3 $\mathrm{MPa}$ and $15.6 \mathrm{MPa}$ respectively. When the content of alkali activator increased from $10 \%$ to $15 \%$, the decreasing tendency of compressive strength was obvious, and the compressive strength at all the ages (3d,7d and $28 d$ ) was decreased with the increase of the amount of alkali activator. The strength decreased by $40.5 \%, 28.17 \%$ and $11.45 \%$, respectively. When the content of alkali activator increased from $15 \%$ to $20 \%$, it decreased by $24 \%, 18.63 \%$ and $15.9 \%$ at different ages $(3 \mathrm{~d}, 7 \mathrm{~d}$ and $28 \mathrm{~d})$.

This is due to when the content of compound alkali activator is low, with the increase of alkali content, it increases the alkalinity of cement paste, promoting the rapid disintegration of fly ash. And the CSH gel was formed with the dissolved calcium ions, and the strength of the cementitious material increased. But when the alkalinity 
reaches a certain value, the amount of the alkali activator increased and the excess $\mathrm{OH}_{-}$in the alkali activated cementitious material system and the strength of fly ash is destroyed, which leads to the decrease of the mechanical strength of cementitious material.

\section{Effect of Styrene / Acrylic Emulsion on Mechanical Properties of Fly Ash - Cement}

In order to improve the mechanical properties of fly ashcement mortar, the styrene - acrylic emulsion was used to improve the mechanical properties. The compressive strength and flexural strength of fly ash - cement mortar were measured according to the mixing ratio of styrene acrylic emulsion.

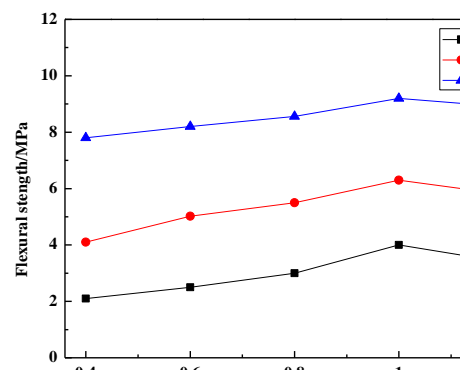

Figure 6. Effect of styrene-acrylic emulsion content on flexural strength

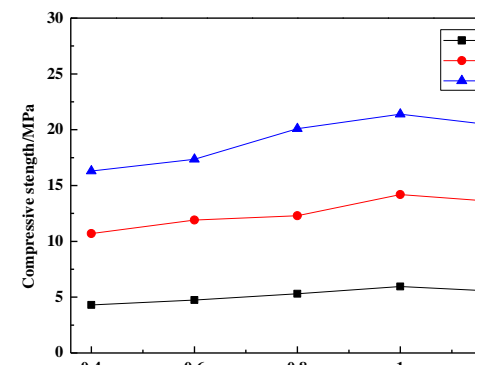

Figure 7. Effect of different styrene-acrylic emulsion content on compressive strength

The effect of different dosage of styrene-acrylic emulsion on the flexural strength of mortar is shown in Fig.7. The compressive strength is shown in Fig.8. In the previous experiment, the flexural strength of the non-doped styrene-acrylic emulsion was $2.9 \mathrm{MPa}, 3.2 \mathrm{MPa}$ and $6.7 \mathrm{MPa}$, the compressive strength was $3.75 \mathrm{MPa}, 7.5 \mathrm{MPa}(3 \mathrm{~d}, 7 \mathrm{~d}$ and $28 \mathrm{~d}$ ) and $13.9 \mathrm{MPa}$. It can be clearly seen that the flexural strength and compressive strength of the mortar samples were improved with the addition of styrene-acrylic emulsion in the range of the test. When the content of styrene - acrylic emulsion is $1 \%$, the compressive strength of specimen $28 \mathrm{~d}$ is $18.11 \mathrm{MPa}$ and the flexural strength is $7.9 \mathrm{MPa}$. The compressive and flexural strength of fly ash - cement mortar are improved respectively $30.29 \%$ and $17.9 \%$ respectively, that is to say, styrene-acrylic emulsion can be used to strengthen toughening effect.

Although the styrene-acrylic emulsion has a significant toughening effect on the fly ash-cement mortar, when the content of the styrene-acrylic emulsion exceeds $1 \%$, the mechanical properties of the prepared mortar decreases with the increase of its content, excess styrene - acrylic emulsion is not conducive to the internal reaction of mortar, resulting in decreased mechanical properties.

\section{CONCLUSIONS}

(1) The addition of lime provides $\mathrm{Ca}^{2+}$ for fly ash hydration, which in turn activates the activity of fly ash to produce ettringite. The strength of fly ash-cement binder increases, but too much $\mathrm{Ca}^{2+}$ causes strength collapse.

(2) The incorporating of fly ash improves the working performance of mortar, but reduces the compressive strength and flexural strength of fly ash - Portland cement blended mortar.

(3) The addition of alkali activator can increase the strength of cementitious material, but excessive alkali activator can destroy cement strength.

(4) The addition of styrene-acrylate emulsion will decrease the mechanical properties of mortar, thus the dosage should not be too large. However, it can also improve the strength of mortar when the content is less than $1 \%$.

\section{ACKNOWLEDGMENT}

The authors would like to acknowledge the financial support from Science and Technology Support Program Major Project of the 'Twelfth Five-Year' Plan of China National Science and Technology (2014BAL03B01-04).

\section{REFERENCES}

[1] Guodong Li, "Characteristics of Structure, Shape and Activity of Fly Ash,” J. Fly Ash Comprehensive Utilization, 1998, 3:35-38.

[2] Shuxia Ren, Bingwen Yao,. Changrui Wang, "Studies on Stimulating Methods and Mechanism of Activity of Fly Ash," J. Fly Ash Comprehensive Utilization, 2008, 4, 50-52.

[3] Junliang Fang, Wenxiong Lu, Caixuan Xu, "Progress in Activiting Techniques and Mechanism Studies of Fly Ash," J. JOURNAL OF SHANGHAI UNIVERSITY (NATURAL SCIENCE), 2002, 8:258260.

[4] Guojun Ke, Xiaofeng Yang, Hong Peng, Fei Jia, Hongtao Yue "Progress of research on chemical activating mechanisms of fly ash," OURNAL OF CHINA COAL SOCIETY, 2005, 30, 3:366-370. 